This item was submitted to Loughborough's Research Repository by the author.

Items in Figshare are protected by copyright, with all rights reserved, unless otherwise indicated.

\title{
Microstructural and mechanical characterisation of laser-welded high-carbon and stainless steel
}

PLEASE CITE THE PUBLISHED VERSION

http://dx.doi.org/10.1007/s00170-015-7111-5

\section{PUBLISHER}

(c) Springer Verlag

\section{VERSION}

AM (Accepted Manuscript)

\section{PUBLISHER STATEMENT}

This work is made available according to the conditions of the Creative Commons Attribution-NonCommercialNoDerivatives 4.0 International (CC BY-NC-ND 4.0) licence. Full details of this licence are available at: https://creativecommons.org/licenses/by-nc-nd/4.0/

\section{LICENCE}

CC BY-NC-ND 4.0

\section{REPOSITORY RECORD}

Esfahani, Mohammadreza Nekouie, Jeremy M. Coupland, and Sundar Marimuthu. 2019. "Microstructural and Mechanical Characterisation of Laser-welded High-carbon and Stainless Steel”. figshare. https://hdl.handle.net/2134/18143. 


\title{
Microstructural and Mechanical Characterisation of Laser Welded High Carbon and Stainless Steel
}

\author{
M.R Nekouie Esfahani*, J Coupland and S Marimuthu \\ Optical Engineering Group, Wolfson School of Mechanical and Manufacturing, \\ Loughborough University, Loughborough, LE11 3TU, United Kingdom
}

\begin{abstract}
Laser welding is becoming an important joining technique for welding of stainless steel to carbon steel and is extensively used across various sectors, including aerospace, transportation, power plants, electronics and other industries. However, welding of stainless steel to high carbon steel is still at its early stage, predominantly due to the formation of hard brittle phases, which undermine the mechanical strength of the joint. This study reports a scientific investigation on controlling the brittle phase formation during laser dissimilar welding of high carbon steel to stainless steel. Attempts have been made to tailor the microstructure and phase composition of the fusion zone through influencing the alloying composition and the cooling rate. Results show that the heat affected zone (HAZ) within the high carbon steel has significantly higher hardness than the weld area, which severely undermines the weld quality. To reduce the hardness of the HAZ, a new heat treatment strategy was proposed and evaluated using a finite element analysis based numerical simulation model. A series of experiments has been performed to verify the developed thermo-metallurgical FEA model and a qualitative agreement of predicted martensitic phase distribution is shown to exist.
\end{abstract}

Keywords: Dissimilar welding; Laser; Microstructure; Hardness; Alloy concentration; FEA Modelling

\footnotetext{
* Corresponding author:

Tel: +44 (0)7576175080, Fax: +44 (0)1509 227648, E-mail: m.esfahani@lboro.ac.uk.
} 


\section{Introduction}

Laser welding of metals and alloys are extensively used in industry due to advantages of controlled heating, narrow weld bead and low heat affected zone (HAZ) [1]. Recently, laser dissimilar welding has been investigated extensively due to the increased demand across various industrial sectors $[2,3]$. However, dissimilar laser welding of metals like high carbon steels (HCS) to stainless steel (SS) is still a challenging task due to the formation of brittle phases and solidification cracking in the fusion zone [4], and martensitic formation in the HAZ of carbon steel [5-7]. These issues can significantly deteriorate the strength of the welded joint and a robust methodology needs to be developed.

Many attempts have been made in the past to address the issues in dissimilar welding. Esfahani et al. [8] studied the martensite formation in dissimilar laser welding of low carbon steel (LCS) to stainless steel and showed that martensitic formation can be controlled by varying the beam positioning away from the weld centre. Nikulina et al. [9], revealed that the martensitic formation at the HAZ can leads to fatigue crack formation and subsequent failure in dissimilar flash butt welded joint of high carbon steel and chrome-nickel steel. The effect of weld chemical composition and heat input was investigated by Muthupandi et al. [10] and demonstrated that the alloying elements concentration have more significant role than the heat input. The final microstructure of the weld bead is a critical factor in laser welding, and David et al. $[11,12]$ showed that it can be influenced by controlling the cooling rate. An investigation conducted by Hajiannia et al. [13] showed that the carbon migration from the HAZ of low alloy steel toward the fusion zone result in formation of martensitic zone in the weld boundary with high hardness value and the optimal hardness value for HCS HAZ was found to be around $650 \mathrm{HV}_{0.05}[14]$.

Most of the previous studies on dissimilar laser welding concentrated on of LCS and SS, and the issues on laser welding of HCS and SS still prevails. The laser welding of HCS and SS is more complex due to the high cooling rate associated with laser processing, which can accelerate the martensitic formation in HCS. The objective of this study is to investigate the significance of alloying composition and cooling rate on controlling the microstructure and mechanical properties of the laser welded HCS to SS joint. Along with experimentation, a finite element analysis (FEA) based numerical model was used to develop a heat treatment methodology that will produce a weld with optimum in-service performance. 


\section{Experimental procedure}

The base materials used in this study were hyper-eutectoid high carbon steel (BS 4659B01) and stainless steel (AISI 316L) sheets with a thickness of $1 \mathrm{~mm}$, such as those commonly used for heat exchangers in petrochemical and refinery industries [13]. The chemical composition of the high carbon steel and the stainless steel is given in Table 1. The sample edges were cleaned and ground prior to welding and were positioned in full contact during the welding.

Table 1 Chemical composition of parent metals in \%wt [15]

\begin{tabular}{|c|ccccccccccccc|}
\hline Elements & $\mathrm{C}$ & $\mathrm{Si}$ & $\mathrm{Tu}$ & $\mathrm{Va}$ & $\mathrm{Mn}$ & $\mathrm{P}$ & $\mathrm{S}$ & $\mathrm{Si}$ & $\mathrm{Cr}$ & $\mathrm{Ni}$ & $\mathrm{Mo}$ & $\mathrm{Nb}$ & $\mathrm{Fe}$ \\
\hline $\mathrm{SS}$ & 0.03 & - & - & - & 2 & 0.01 & 0.03 & 1 & 18.02 & 10.15 & $2-3$ & 0.09 & Bal. \\
\hline HCS & 0.95 & 0.4 & 0.5 & 0.15 & 1.2 & 0.045 & 0.045 & 0.011 & 0.55 & 0.035 & 0.003 & 0.001 & Bal. \\
\hline
\end{tabular}

Dissimilar conduction mode laser welds were made on $50 \times 50 \times 1 \mathrm{~mm}$ metal sheets using a continuous wave $(\mathrm{CW})$ carbon di-oxide $\left(\mathrm{CO}_{2}\right)$ laser. A schematic diagram of the laser welding set-up is shown Fig. 1. A coaxial nozzle with a focusing lens of $127 \mathrm{~mm}$ focal length was used to focus the beam onto the specimen surface. The focus spot size of the laser beam was found to be $0.5 \mathrm{~mm}$ with Gaussian intensity distribution, and the nozzle-workpiece standoff distance was kept constant at $5 \mathrm{~mm}$. Initial trial experiments were carried out to identify feasible processing parameters for the laser welding of HCS to SS. Initial trial experiments showed optimal shielding with argon gas at 2bar gas pressure and 21/min, and these parameters were used for all experimentation. A CNC controlled table was used to move the samples relative to the laser nozzle.

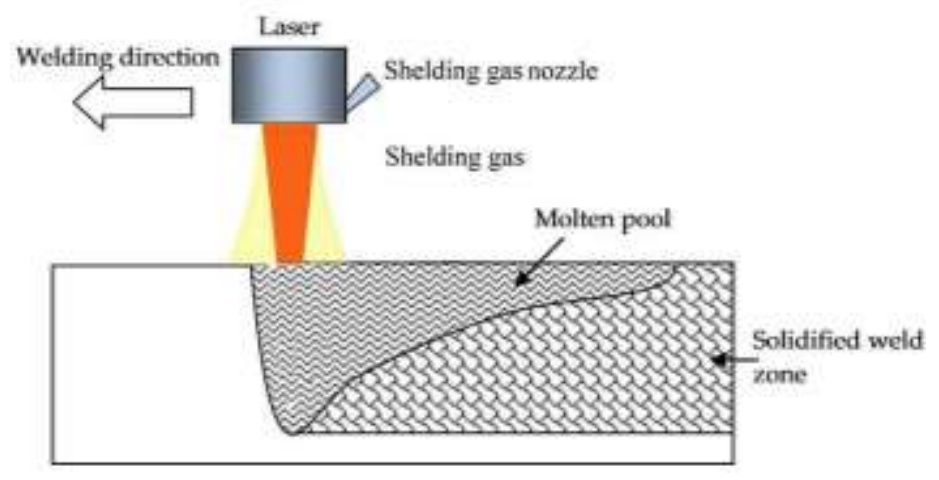

Fig. 1. Schematic diagram of a laser welding process 
A total of 80 experiments were performed with various parameters as per table 2. Each experiment was repeated twice to confirm the repeatability. Various specific point energies (that will result in a wide range of cooling rate) were chosen, so as to investigate the influence of cooling rate on weld microstructure. The beam position with reference to the joint was shifted by up to $\pm 0.4 \mathrm{~mm}$ with an increments of $0.05 \mathrm{~mm}$, to study the influence the alloying concentration [8] on weld quality. The specific point energy was controlled based on the scanning speed with constant laser power [16] . Specific point energy (Equation 1) takes into account welding speed $(V)$, laser beam diameter $(D)$ and laser power $(P)$ and is given by Eq.1 [16]:

Specific Point energy $=\frac{P \times D}{V}$

Eq. 1

Table 2 Laser dissimilar welding parameters used in present investigation

\begin{tabular}{|c|c|c|c|c|}
\hline & $\begin{array}{c}\text { Speed } \\
(\mathrm{mm} / \mathrm{s})\end{array}$ & $\begin{array}{c}\text { Power } \\
(\mathrm{W})\end{array}$ & $\begin{array}{c}\text { Specific point } \\
\text { energy }(\mathrm{J})\end{array}$ & Beam offset $(\mathrm{mm})$ \\
\hline 1 & 5 & 500 & 50 & $\pm 0.4 \mathrm{~mm}$, increments of $0.05 \mathrm{~mm}$ \\
\hline 2 & 7.5 & 500 & 33 & $\pm 0.4 \mathrm{~mm}$, increments of $0.05 \mathrm{~mm}$ \\
\hline 3 & 10 & 500 & 25 & $\pm 0.4 \mathrm{~mm}$, increments of $0.05 \mathrm{~mm}$ \\
\hline 4 & 12.5 & 500 & 20 & $\pm 0.4 \mathrm{~mm}$, increments of $0.05 \mathrm{~mm}$ \\
\hline 5 & 15 & 500 & 17 & $\pm 0.4 \mathrm{~mm}$, increments of $0.05 \mathrm{~mm}$ \\
\hline
\end{tabular}

The cooling rates $\left(\frac{\partial T}{\partial t}\right)_{x}$ values used in this study were calculated from one dimensional heat transfer equation proposed by Adams Jr [17], which takes into account the effect of laser power $(P)$, welding speed $(V)$, thermal conductivity $(K)$, liquidus temperature $(T)$ and preheating temperature $\left(T_{0}\right)$ and can be expressed as [18]:

$\left(\frac{\partial T}{\partial t}\right)_{x}=\left(\frac{\partial T}{\partial x}\right)_{t}\left(\frac{\partial x}{\partial t}\right)_{T}=-2 \pi K V \frac{\left(T-T_{0}\right)^{2}}{P}$ Eq. 2

The thermal conductivity (in $\mathrm{W} /\left(\mathrm{m}^{\circ} \mathrm{C}\right)$ ) of the weld zone in the cooling rate equation was calculated based on the alloying concentration (dilution) of the weld zone [8] and the preheating temperature was taken as room temperature (in ${ }^{\circ} \mathrm{C}$ ). The cooling rates (Equation 2 ) were calculated for a liquidus temperature of $1450^{\circ} \mathrm{C}$.

The laser welded samples were prepared for metallographic analysis as per ASTM E3-11 standards [19]. Metallographic samples were etched using three etchants. The HCS side of the 
weldment was etched using Nital 5\% regent, stainless steel side was etched using Kalling's No.2 (5 $\mathrm{g} \mathrm{CuCl}_{2}, 100 \mathrm{ml} \mathrm{HCl}, 100 \mathrm{ml}$ ethanol), and the fusion zone was etched using (Ferric chloride $5 \mathrm{~g} \mathrm{FeCl}_{3}, 50 \mathrm{ml} \mathrm{HCL}, \mathrm{HNO}_{3}$ ). Microstructural characterizations of dissimilar joints were performed on their cross-sections using an optical microscopy and a scanning electron microscopy accompanied by energy dispersive $\mathrm{x}$-ray spectroscopy. Vickers hardness profile of the weld metal and heat affected zone was measured using a KV400 micro-hardness tester with a load of $50 \mathrm{~g}$. XRD analyses were carried out in order to identify the phases of the samples and to determine their relative amount using the integral breadth method.

\section{Results and Discussion}

Fig. 2 illustrates the optical microstructure of a typical laser welded HCS-SS joint. Fig. 2a and $2 \mathrm{~b}$ shows the optical microstructure of as received (parent material) SS and HCS respectively. The microstructure of HCS consists of fine pearlite and spheroidal cementite in a ferrite matrix, and SS contains equiaxed austenitic grains $(\gamma)$.

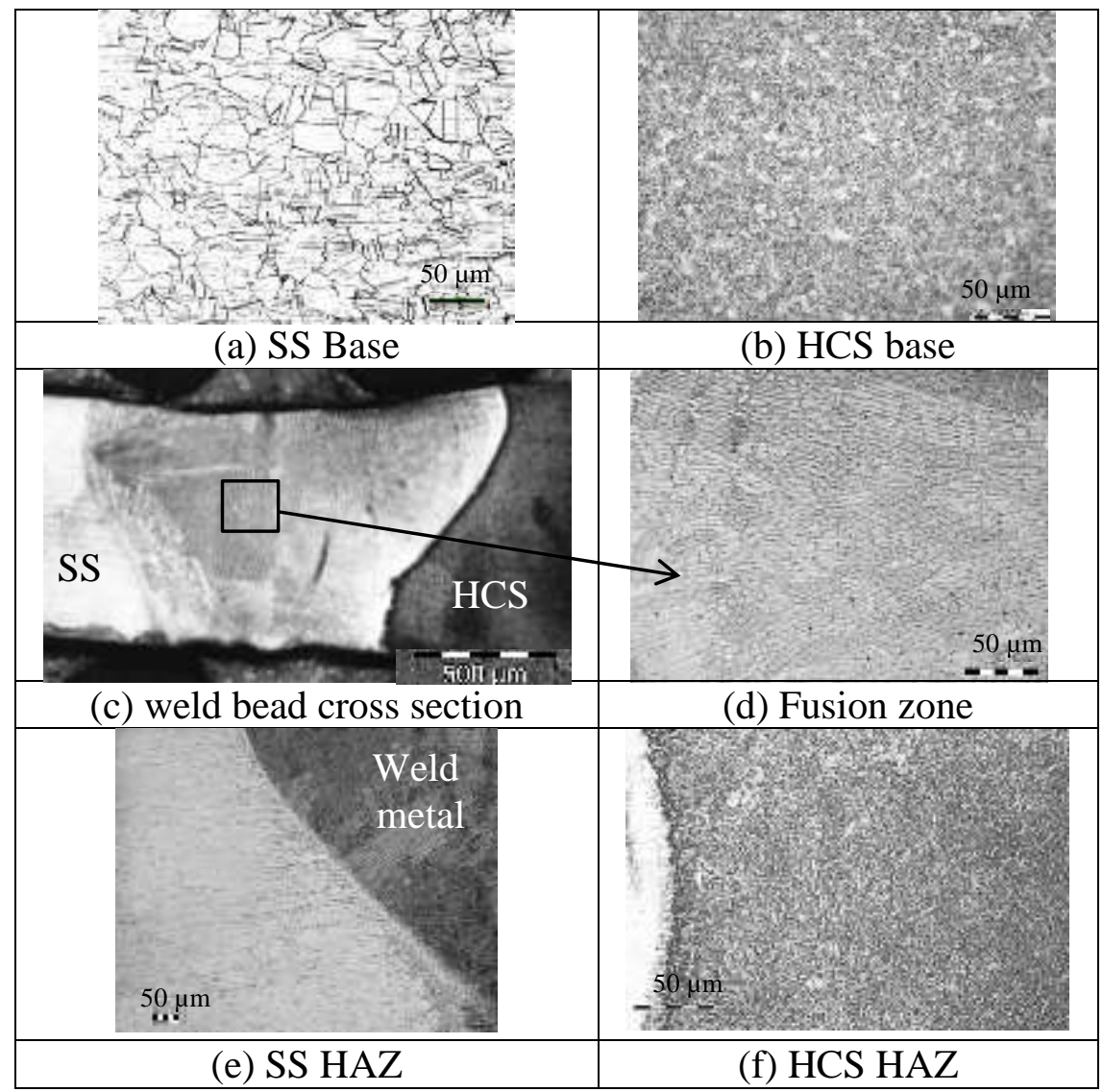

Fig. 2. Optical micrograph of the parent metals and microstructures gradient in the HAZ of HCS (power $=500 \mathrm{~W}$, welding speed $=10 \mathrm{~mm} / \mathrm{s}$, beam offset $=0 \mathrm{~mm}$ ) 
Fig. 2c shows the dissimilar weld bead and Fig. 2d illustrates the fusion zone which is predominantly of columnar dendrites with nucleated fusion boundary. As noted from the figure, the microstructure of fusion zone was predominantly homogeneous, which is attributed to the high magnitude of melt pool convention in the fusion zone, which homogenizes the fusion zone microstructure [8]. Fig. 2e and $2 f$ show the optical microstructure of the SS HAZ and the HCS HAZ respectively. The microstructure of the HCS HAZ shows significant variations, possibly attributed to the high thermal gradient and high carbon content in HCS. Also noted from the figure is that the microstructure variation is not significant in the HAZ of SS due to non-transformable nature of austenitic stainless steel [8]. Some austenite recrystallized grains was seen in the SS HAZ (Fig. 2e) but they are not of significant concern [20].

Table 3 summarises the key results of the experimentation (effect of the cooling rate and alloying element concentration on the consequent microstructure of the weld zone) performed using the parameters shown in table 2. The results were organised, so as to study the effect of alloying concentration with constant cooling rate, and the effect of cooling rate with constant alloying concentration. The alloying concentration $(\mathrm{Cr} \%$; Ni\%) given in Table 3 was established through EDS analysis of the weld bead, and the microstructure was established by optical microscopy. The cooling rate given in Table 3 was calculated using equation 2 . The variation of cooling rate with beam offset (alloying concentration) at each level of specific point energy was insignificant $\left(0.009 \pm 10^{6}{ }^{\circ} \mathrm{C} / \mathrm{s}\right)$ and an average was considered.

Table 3 Effect of cooling rate and alloying concentration on weld microstructure

\begin{tabular}{|c|c|c|c|c|c|c|}
\hline \multirow{2}{*}{$\begin{array}{c}\text { Specific } \\
\text { point } \\
\text { energy }(\mathrm{J})\end{array}$} & \multicolumn{5}{|c|}{ Weld alloying element concentration [wt\%] } & \multirow{2}{*}{ 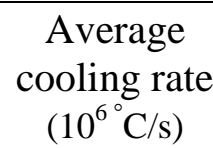 } \\
\hline & $\begin{array}{l}\mathrm{Cr} 13 \% \\
\mathrm{Ni} 7 \%\end{array}$ & $\begin{array}{l}\text { Cr } 11 \% \\
\text { Ni } 6 \%\end{array}$ & $\begin{array}{l}\text { Cr } 9.6 \% \\
\text { Ni } 5.2 \%\end{array}$ & $\begin{array}{l}\mathrm{Cr} 7.37 \% \\
\mathrm{Ni} 3.8 \%\end{array}$ & $\begin{array}{l}\mathrm{Cr} 4 \% \\
\mathrm{Ni} 2.1 \%\end{array}$ & \\
\hline \multirow{2}{*}{50} & $(\gamma+\delta)$ & $(\gamma+\delta)$ & $(\gamma+M)$ & $(\gamma+M)$ & $(M)$ & \multirow[t]{2}{*}{0.028} \\
\hline & -0.4 & -0.3 & -0.25 & 0 & 0.1 & \\
\hline \multirow{2}{*}{33} & $(\gamma+\delta)$ & $(\gamma+\delta)$ & $(\gamma+M)$ & $(\gamma+M)$ & $(M)$ & \multirow[t]{2}{*}{0.043} \\
\hline & -0.35 & -0.25 & -0.1 & 0.1 & 0.15 & \\
\hline \multirow{2}{*}{25} & $(\gamma+\delta)$ & $(\gamma+\delta)$ & $(M)$ & $(M)$ & $(M)$ & \multirow{2}{*}{0.057} \\
\hline & -0.3 & -0.2 & 0 & 0.15 & 0.2 & \\
\hline \multirow{2}{*}{20} & $(\gamma+\delta)$ & $(\gamma+M)$ & $(M)$ & $(M)$ & $(M)$ & \multirow{2}{*}{0.071} \\
\hline & -0.1 & 0 & 0.1 & 0.25 & 0.3 & \\
\hline \multirow{4}{*}{17} & $(\gamma+\delta)$ & $(\gamma+M)$ & $(M)$ & $(M)$ & $(M)$ & \multirow{2}{*}{0.085} \\
\hline & 0 & 0.15 & 0.2 & 0.3 & 0.4 & \\
\hline & \multicolumn{5}{|c|}{$\begin{array}{c}\gamma+\delta=\text { Austenitic-Ferritic } ; \gamma+M=\text { Austenitic-Martensitic; } M= \\
\text { Martensitic }\end{array}$} & \\
\hline & \multicolumn{5}{|c|}{ Beam offset toward stainless steel (-), Beam offset toward carbon steel (+) } & \\
\hline
\end{tabular}


As can be seen from the table, three distinct microstructures of $(\gamma+\delta, \gamma+M, M)$ were noticed in the weld bead. Decrease in alloying content results in change of the microstructure from austenitic-ferritic $(\gamma+\delta)$ to completely martensitic $(M)$. Fig. 3a, 3b and 3c illustrate the optical micrograph of various alloying elements at a constant cooling rate of $0.057 \times 10^{6}{ }^{\circ} \mathrm{C} / \mathrm{s}$.

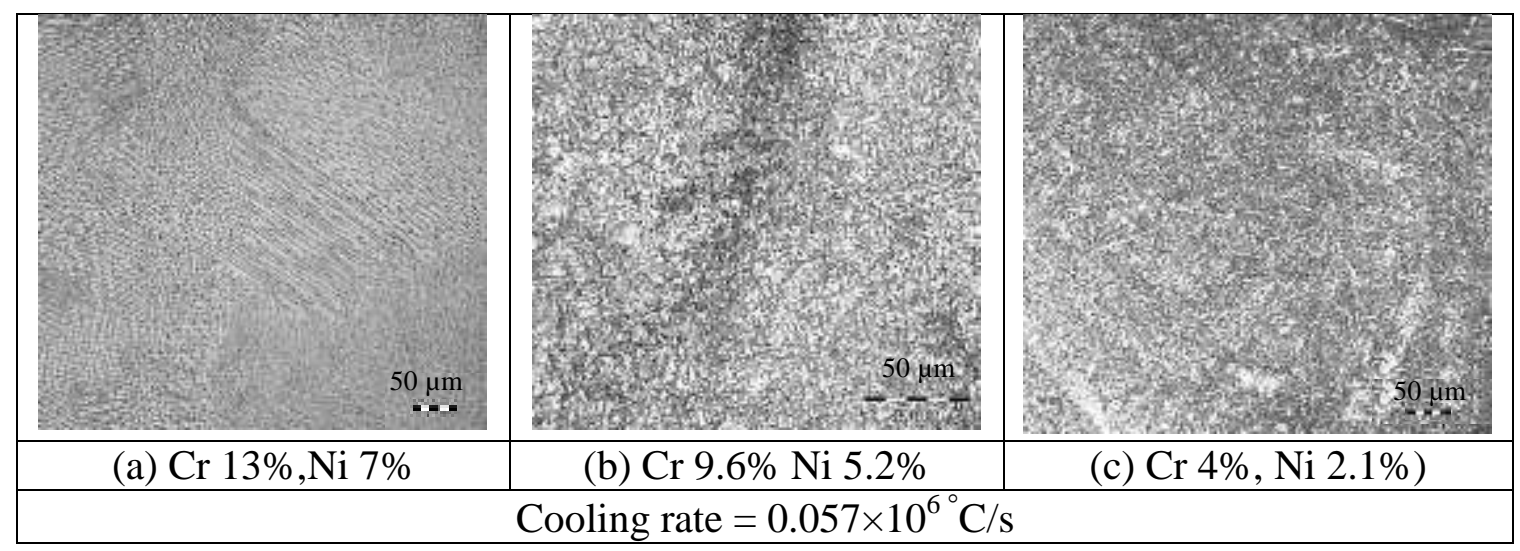

Fig. 3. Effect of alloying concentration on the microstructure (a) primary austenitic $\gamma$ dendrites (light) with interdendritic $\delta$ ferrite, (b) Martensite, (c) Martensite

Fig. 4 shows the effect of cooling rate on microstructural variation at an alloying composition of $\mathrm{Cr} 9.6 \%$, and $\mathrm{Ni} 5.2 \%$. Variation of cooling rate from 0.028 to $0.085\left(10^{6}\right.$ $\left.{ }^{\circ} \mathrm{C} / \mathrm{s}\right)$, resulted in transformation of microstructure from austenitic-martensitic $(\gamma+M)$ to predominantly martensitic $(M)$. However, at lower alloying concentration (below $\mathrm{Cr} 9.6 \%$, Ni 5.2\%), the effect of cooling rate on the final microstructure becomes much more significant, and experimental parameters at this range should be avoided.

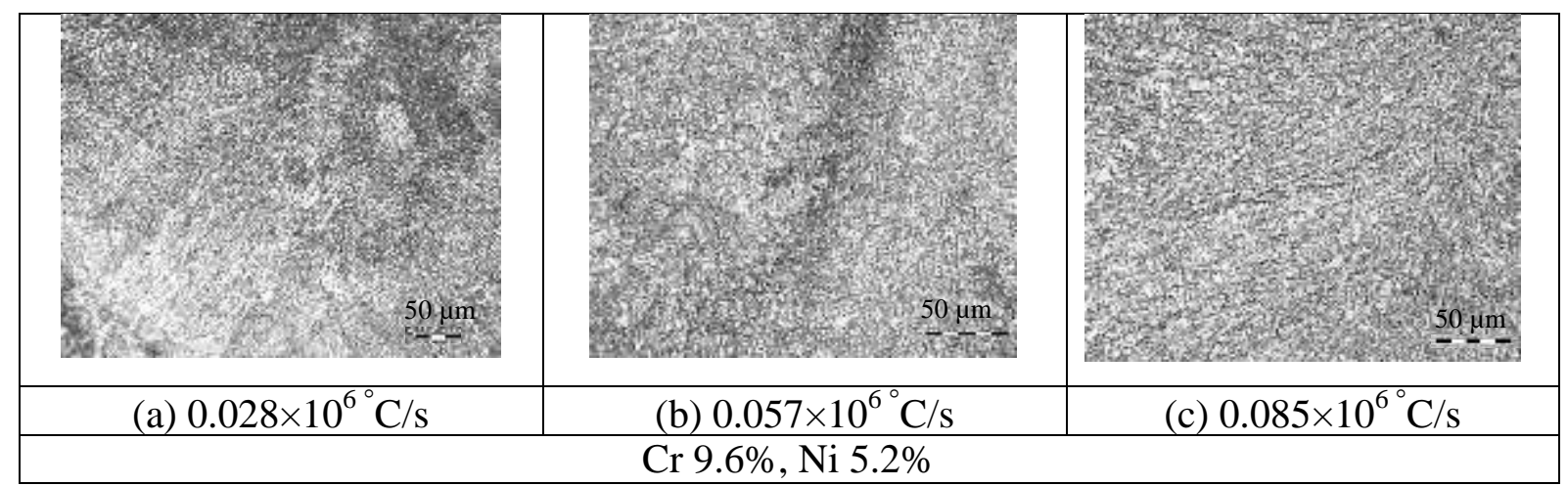

Fig. 4. Effect of cooling rate on the microstructure (a) austenitic-martensitic microstructure,

(b) Martensite, (c) Martensite

The hardness measurement results shown in Fig. 5, confirm the observation made with optical microscopy (Table-3). As can be seen from the Fig. 5, increase in cooling rate resulted in 
increased hardness values. However, the increase in hardness values at higher alloying level should be attributed to the finer grain structure of the austenite, while at low alloying level it is due to martensitic formation. Also, at higher alloying level, the alloying elements restrict the transition of the austenite phase and the microstructure remained predominantly austenitic-ferritic $(\gamma+\delta)$ irrespective of the cooling rate. The formation of martensite in HCSSS joint can cause defects such as cracks in fusion zone which can undermine the service performance of the joint [21]. To achieve a weld bead of predominantly austenitic phase, it is essential to maintain higher alloying composition (greater than $\mathrm{Cr} 11 \%$, Ni 6\%) and cooling rate $0.057 \times 10^{6} \mathrm{C} / \mathrm{s}$. Sample with $25 \mathrm{~J}$ specific point energy and offset of -0.2 toward SS provided such optimum conditions.

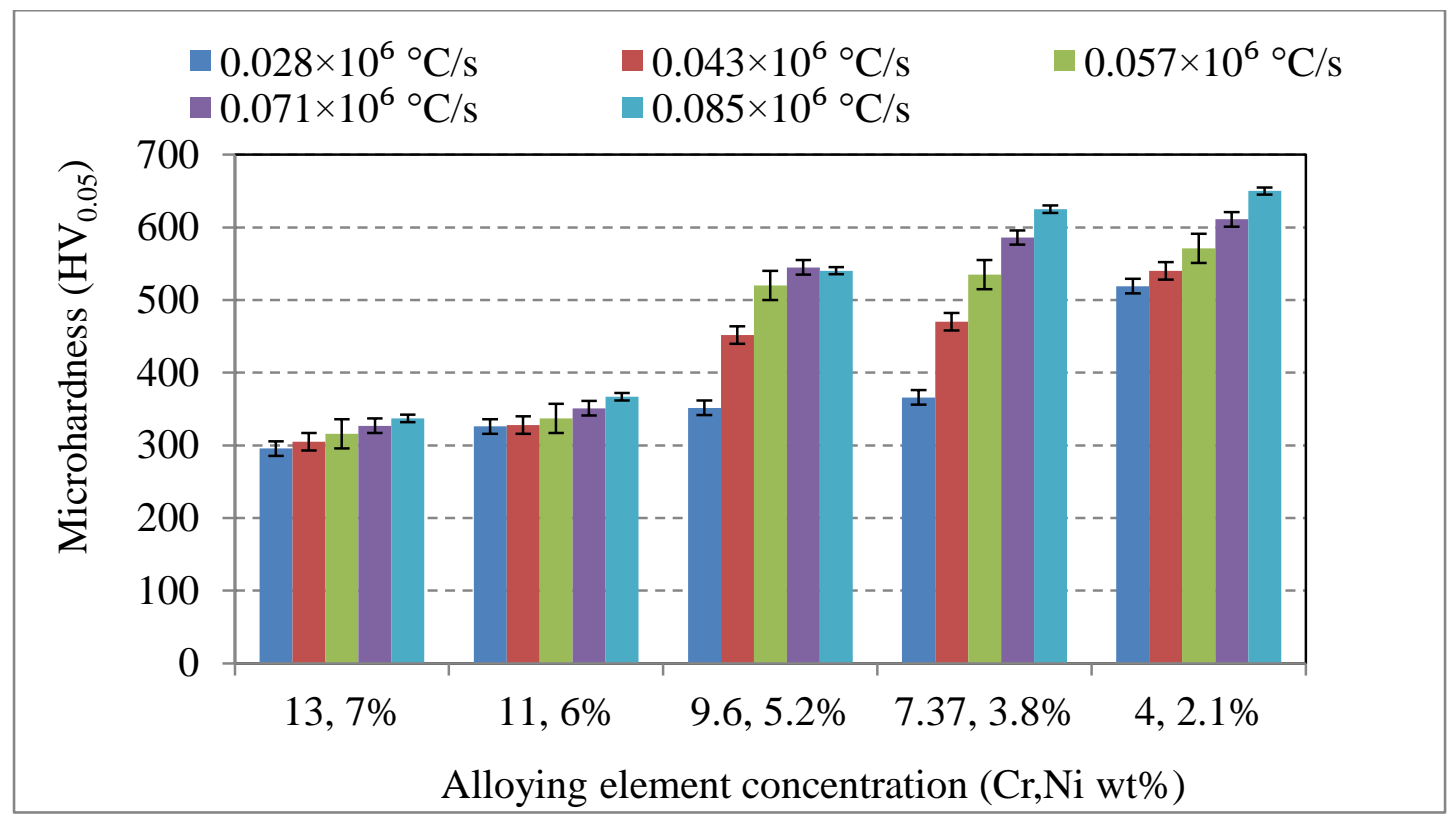

Fig. 5. Effect of cooling rate and alloying concentration on weld microhardness

The hardness profile along the middle of the welded joint for cooling rates of $0.028,0.057$, and $0.085 \times 10^{6} \mathrm{C} / \mathrm{s}$, with a constant alloying composition of $(\mathrm{Cr} 11 \%, \mathrm{Ni} 6 \%)$ is shown in Fig. 6. As can be seen, a significant spike in hardness was observed in the HCS HAZ. The high carbon content along with the formation of martensitic structure (as a result of high cooling rate involved in laser welding) in the HCS HAZ resulted in a spike in hardness at the HCS HAZ. Irrespective of the weld characteristic, the spike in hardness of the HAZ can result in poor joint performance [22]. 


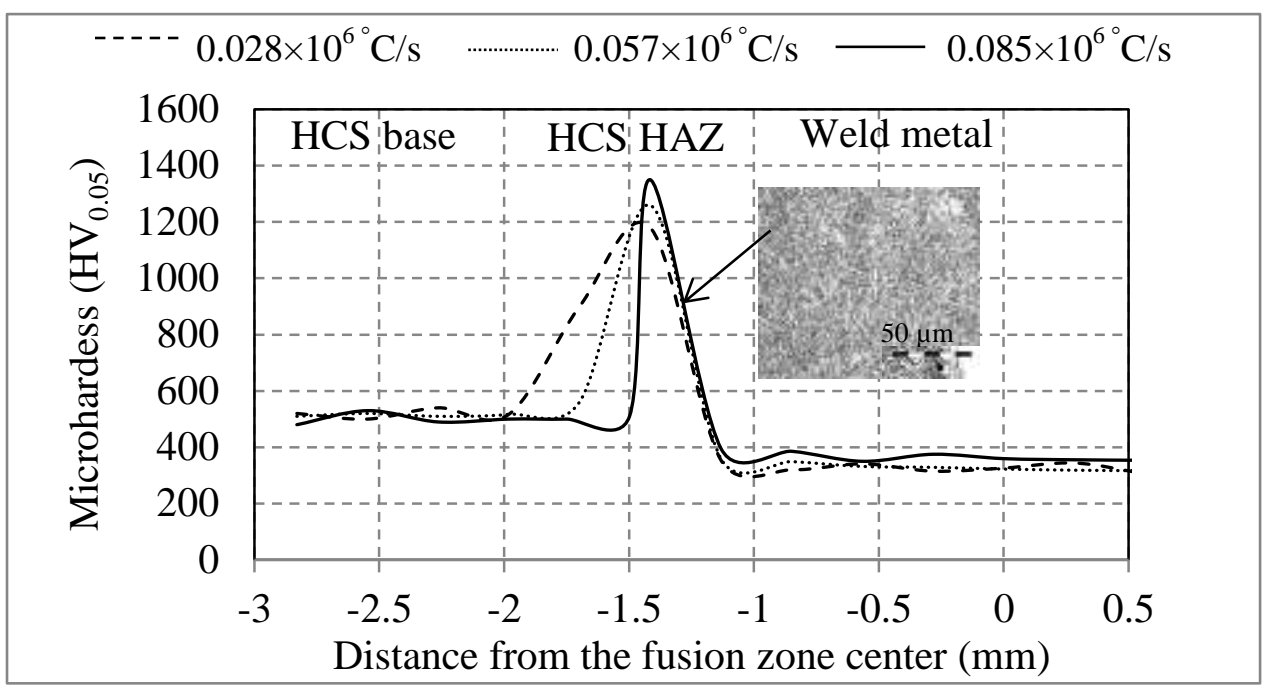

Fig. 6. Micro-hardness profile of the dissimilar weld at various cooling rates $(\mathrm{Cr} 11 \%$, Ni $6 \%)$

All the samples show similar results, and the spike in the HAZ hardness cannot be controlled just by changing the alloying concentration or fusion zone cooling rate. As noted from the results, laser parameters have very little effect on HAZ cooling rate and subsequent HAZ microstructure. Control of the cooling rate of the HAZ is essential to address the spike in the HCS HAZ, and heat treatment using additional source was identified as one of the method for control of the cooling rate.

A numerical model was developed based on finite element (FEA) formulation, to establish the optimum heat treatment methodology and resulting cooling rate of the HCS HAZ so as to address the martensitic formation. Detailed description of this model is beyond the present scope of this paper, however, the FE model and methodology of simulation is similar to the one discussed by Deng $[22,23]$. The sequentially coupled thermal-metallurgical FEA model was [22, 24, 25] solved using ANSYS codes. The dimensions of the work piece considered in numerical analysis is same as described in section 2, and the thermo-physical properties can be noted from Attarha [26] and Lee [27]. In laser welding of HCS, the martensitic transformation of the solid material (HAZ) occurs during the cooling cycle, between $800^{\circ} \mathrm{C}$ and $500^{\circ} \mathrm{C}\left(\nabla \mathrm{t}_{8 / 5}\right)$ [28]. A subroutine was used within the ANSYS code to relate $\nabla \mathrm{t}_{8 / 5}$ of each node, to the martensite fraction obtained from HCS CCT diagrams [22]. A Gaussian heat flux was used to represent the laser beam and convection heat loss was taken into account on all the surfaces. A secondary heat source (as temperature boundary condition) was used in the FEA model to achieve the controlled cooling rate. The secondary heat source maintains the welded joint at $800^{\circ} \mathrm{C}$ till the end of welding cycle, and cools the joint with a controlled 
cooling rate. After initial trials, three set of scenarios where investigated i.e. Case-I: uncontrolled cooling- same as experimentation $\left(\nabla \mathrm{t}_{8 / 5}=0.1 \mathrm{sec}\right)$; Case-II: controlled cooling rate of $\nabla \mathrm{t}_{8 / 5}=40 \mathrm{sec}$; Case-III: controlled cooling rate of $\nabla \mathrm{t}_{8 / 5}=140 \mathrm{sec}$. The FEM analysis was performed for optimal welding condition, i.e. speed of $5 \mathrm{~mm} / \mathrm{s}$, laser power of $500 \mathrm{~W}$ and beam offset of $0.2 \mathrm{~mm}$. In-line with the experimental parameter, the laser spot diameter of the beam over the sample surface was maintained at $0.5 \mathrm{~mm}$.

Fig. 7 shows the thermal history of the HAZ for various controlled cooling time $\left(\nabla \mathrm{t}_{8 / 5}\right)$. Fig. 8a-c shows the contour image of the martensitic fraction obtained for various controlled cooling times of $0.1 \mathrm{~s}, 40 \mathrm{~s}$ and $140 \mathrm{~s}$. The contour image was plotted after the substrate reaches the room temperature. As can be seen from the figure, controlling of the cooling time results in a significant decrease in martensite fraction (from $100 \%$ to $20 \%$ ). The increase in controlled cooling time, promotes the diffusion of carbon atoms out of the crystal structure, resulting in less martensite formation [18].

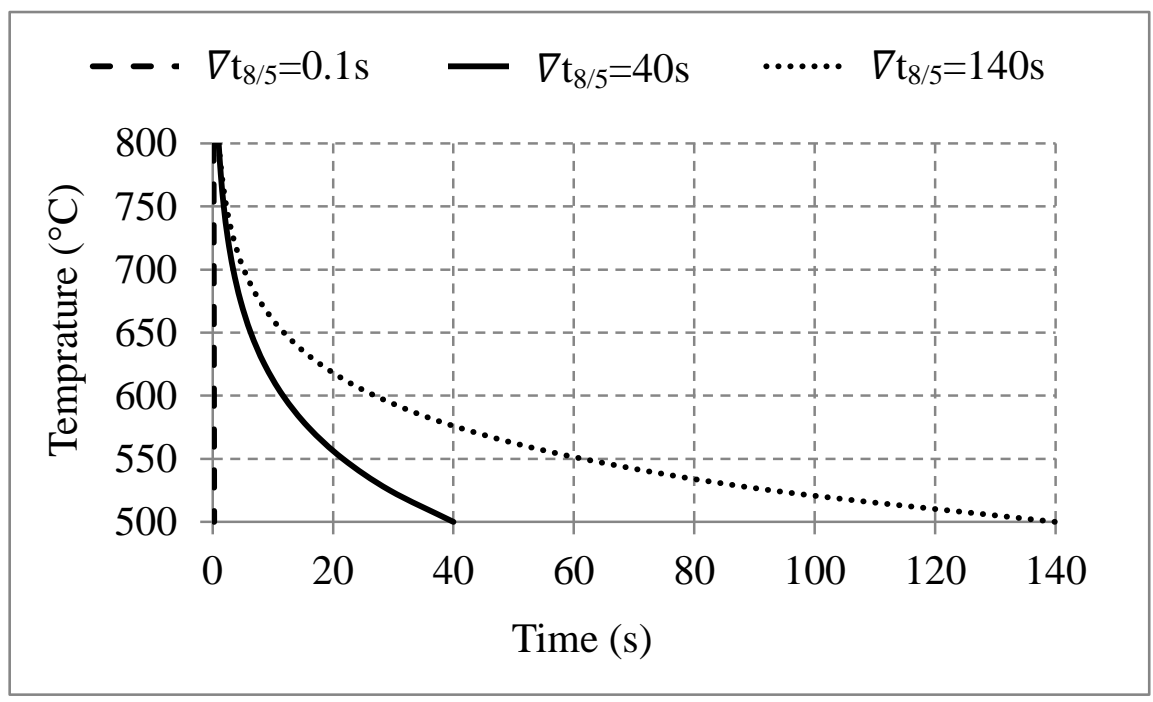

Fig. 7. Temperature cycle over the HCS HAZ weld for various controlled cooling time

$$
\left(\nabla \mathrm{t}_{8 / 5}=0.1 \mathrm{~s}, 40 \mathrm{~s} \text {, and } 140 \mathrm{~s}\right)
$$




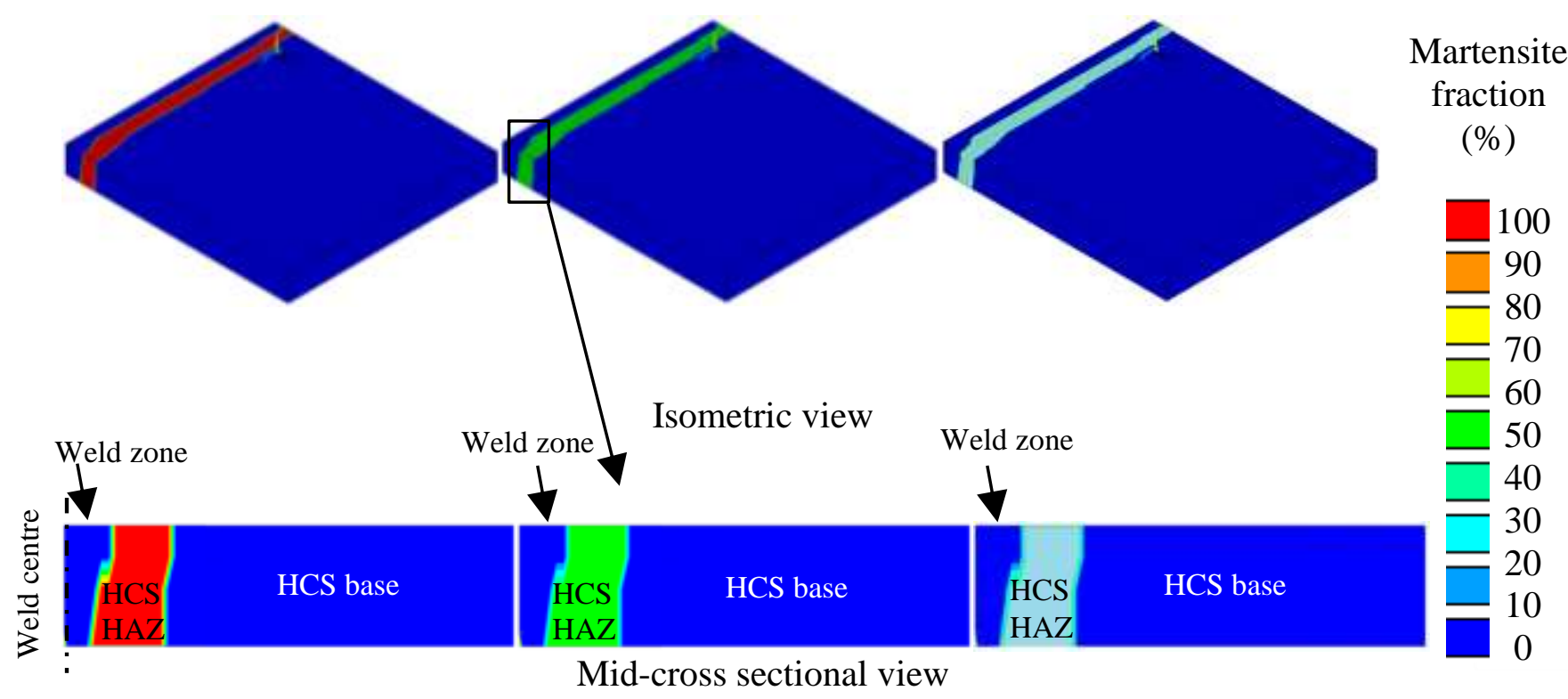

(a)

(b)

(c)

Fig. 8. Martensite fraction (\%) in HCS HAZ for various controlled cooling times

(a) $\nabla \mathrm{t}_{8 / 5}=0.1 \mathrm{~s}$, (b) $\nabla \mathrm{t}_{8 / 5}=40 \mathrm{~s}$ and (c) $\nabla \mathrm{t}_{8 / 5}=140 \mathrm{~s}$

Direct validation of the numerical simulation results (Case-II and III-with same heat treatment method) was beyond the scope of this study. However, experiments were performed using a stationary laser beam (similar to spot welding-but with varying power levels to follow the trend of the cooling rate in Fig. 7) which gives similar cooling rate at the $\operatorname{HCS~HAZ~}\left(\nabla \mathrm{t}_{8 / 5}\right)$.

Fig. 9 shows the comparison of martensite fraction obtained from simulation and experimentation (X-ray diffractometer). In agreement with the experimental results, the FEA model predicts the decrease in martensitic fraction with increase in controlled cooling time $\left(\nabla \mathrm{t}_{8 / 5}\right)$. The decrease in the martensite volume fraction is attributed to the slower cooling rate, which provides sufficient time for the carbon to diffuse out of the crystal structure [29]. As can be seen from the Fig. 10, the optimum HCS HAZ hardness $\left(650 \mathrm{HV}_{0.05}\right.$ [18]) was obtained at the heat treatment time of $\nabla \mathrm{t}_{8 / 5}=40 \mathrm{~s}$. Fig. 10 depicts the hardness profiles and optical microscopic image of the spot weld experimental sample with controlled cooling time 
$\left(\nabla t_{8 / 5}\right)$ of $40 \mathrm{~s}$. The results of the hardness and optical metallography of heat treated HAZ agrees qualitatively with the FEA model.

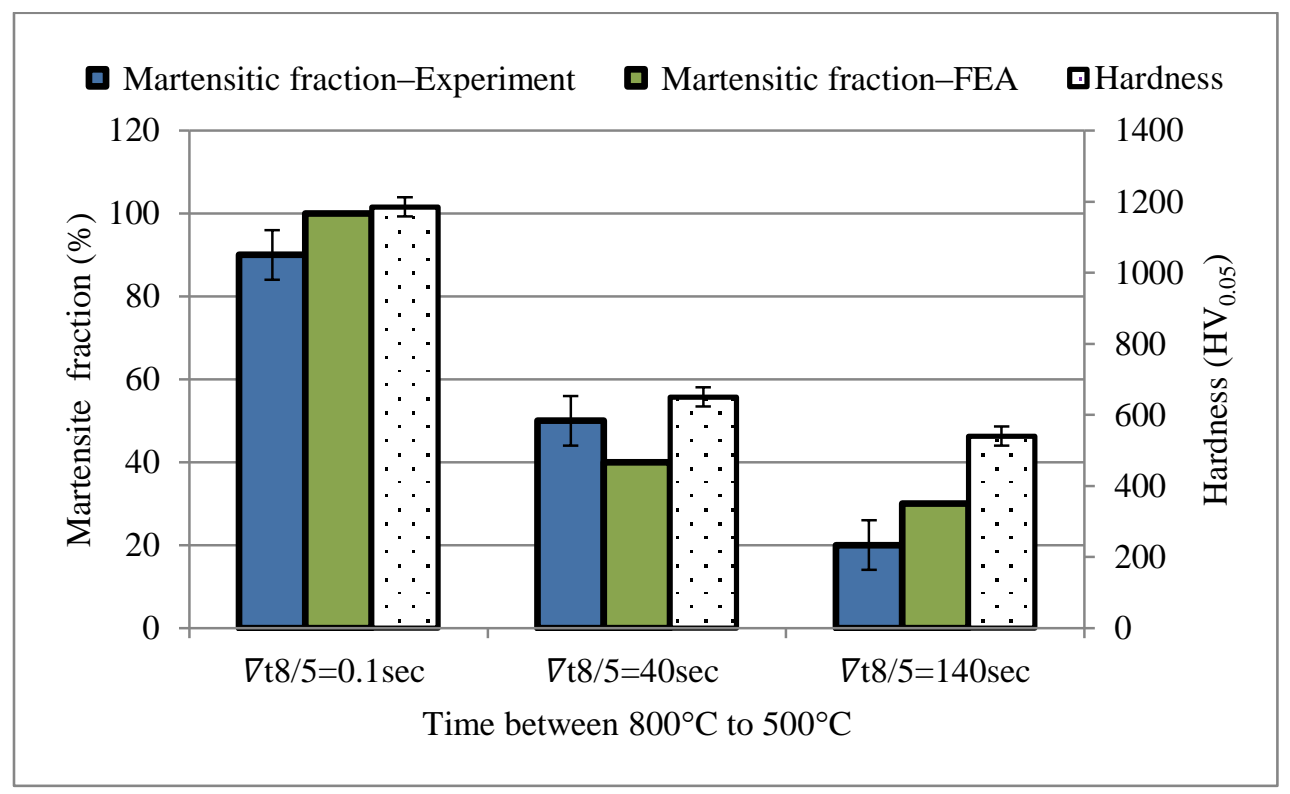

Fig. 9. Calculated and measured martensite fraction (\%) in HCS HAZ

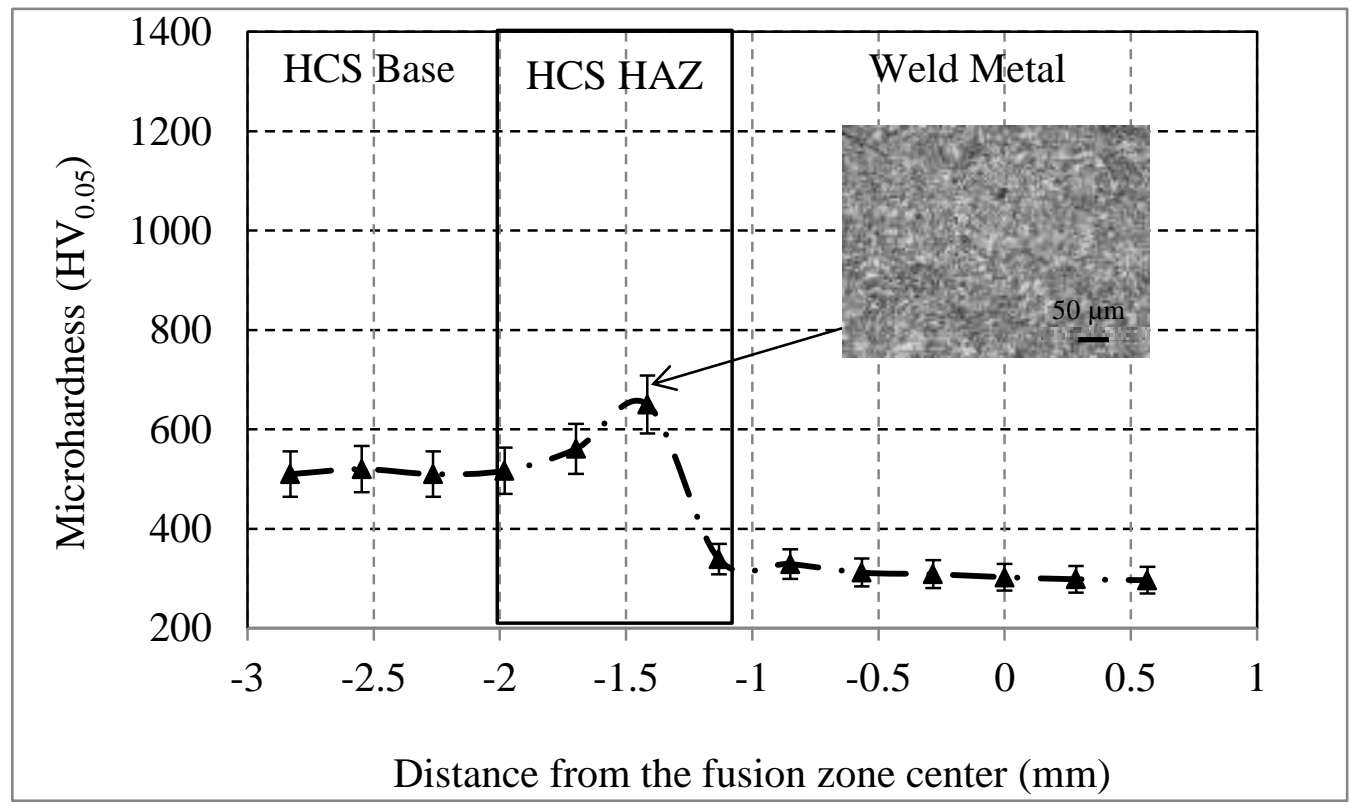

Fig. 10. Microhardness profile and optical micrograph of the HCS zone obtained with controlled cooling rate $\left(\nabla \mathrm{t}_{8 / 5}=40 \mathrm{~s}\right)$ 


\section{Conclusion}

An experimental investigation was performed to establish the methodology of controlling the microstructure and mechanical properties of a laser welded joint between high carbon and stainless steel. The results obtained in this work are summarized below:

- This investigation has demonstrated the feasibility of producing a laser welded joint between high carbon steel and austenitic stainless steel that is predominantly homogeneous and of austenitic microstructure.

- The alloying composition and cooling rate significantly influences the final microstructure of the dissimilar weld zone.

- At normal laser welding conditions, hard brittle martensitic phase was observed in the HCS HAZ and cannot be controlled by varying the laser processing parameters.

- The martensitic formation in HCS HAZ can be controlled by using suitable heat treatment methods and the optimal $\nabla \mathrm{t}_{8 / 5}$ cooling time to achieve desirable HCS-SS welded joint was found to be around 40s.

- FEA analysis can be used to estimate and control the martensitic fraction in laser welding of HCS. 


\section{References:}

[1] S. Baghjari, S. Akbari Mousavi, Effects of pulsed Nd: YAG laser welding parameters and subsequent post-weld heat treatment on microstructure and hardness of AISI 420 stainless steel, Materials \& Design, 43 (2013) 1-9.

[2] S. Missori, C. Koerber, Laser beam welding of austenitic-ferritic transition joints, Welding Journal-Including Welding Research Supplement, 76 (1997) 125-134.

[3] H. Ming, Z. Zhang, J. Wang, E.-H. Han, W. Ke, Microstructural characterization of an SA508-309L/308L-316L domestic dissimilar metal welded safe-end joint, Materials Characterization, 97 (2014) 101-115.

[4] J.C. Lippold, Welding Metallurgy and Weldability, John Wiley \& Sons2014.

[5] P. Marashi, M. Pouranvari, S. Amirabdollahian, A. Abedi, M. Goodarzi, Microstructure and failure behavior of dissimilar resistance spot welds between low carbon galvanized and austenitic stainless steels, Materials Science and Engineering: A, 480 (2008) 175-180.

[6] E.E.S. Ng, Laser welding of high carbon steels, University of Glasgow1999.

[7] F. Zhang, B. Lv, B. Hu, Y. Li, Flash butt welding of high manganese steel crossing and carbon steel rail, Materials Science and Engineering: A, 454 (2007) 288-292.

[8] R. Esfahani, J. Coupland, S. Marimuthu, Microstructure and mechanical properties of a laser welded low carbon-stainless steel joint, Journal of Materials Processing Technology, (2014).

[9] A. Nikulina, A. Bataev, A. Smirnov, A. Popelyukh, V. Burov, S. Veselov, Microstructure and fracture behaviour of flash butt welds between dissimilar steels, Science and Technology of Welding and Joining, (2014).

[10] V. Muthupandi, P. Bala Srinivasan, S. Seshadri, S. Sundaresan, Effect of weld metal chemistry and heat input on the structure and properties of duplex stainless steel welds, Materials Science and Engineering: A, 358 (2003) 9-16.

[11] S. David, J. Vitek, R. Reed, T. Hebble, Effect of rapid solidification on stainless steel weld metal microstructures and its implications on the Schaeffler diagram, Oak Ridge National Lab., TN (USA)1987.

[12] A. Zambon, F. Bonollo, Rapid solidification in laser welding of stainless steels, Materials Science and Engineering: A, 178 (1994) 203-207.

[13] I. Hajiannia, M. Shamanian, M. Kasiri, Microstructure and mechanical properties of AISI 347 stainless steel/A335 low alloy steel dissimilar joint produced by gas tungsten arc welding, Materials \& Design, 50 (2013) 566-573. 
[14] H. Bande, G. L'Espérance, M. Islam, A. Koul, Laser surface hardening of AISI 01 tool steel and its microstructure, Materials Science and Technology, 7 (1991) 452-457.

[15] W. Zhang, G. Roy, J. Elmer, T. DebRoy, Modeling of heat transfer and fluid flow during gas tungsten arc spot welding of low carbon steel, Journal of Applied Physics, 93 (2003) 3022-3033.

[16] W. Suder, S. Williams, Investigation of the effects of basic laser material interaction parameters in laser welding, Journal of Laser Applications, 24 (2012) 032009.

[17] C.M. Adams Jr, Cooling rates and peak temperatures in fusion welding, Welding J.(NY), 37 (1958).

[18] S. Kou, Welding metallurgy, Cambridge Univ Press1987.

[19] P. Peasura, L. Sumarn, Effect of Post Weld Heat Treatment on Carbon Steel AISI 1050 in Heat Effected Zone, Advanced Materials Research, 650 (2013) 612-615.

[20] M. Torkamany, J. Sabbaghzadeh, M. Hamedi, Effect of laser welding mode on the microstructure and mechanical performance of dissimilar laser spot welds between low carbon and austenitic stainless steels, Materials \& Design, 34 (2012) 666-672.

[21] M. Jafarzadegan, A. Feng, A. Abdollah-zadeh, T. Saeid, J. Shen, H. Assadi, Microstructural characterization in dissimilar friction stir welding between 304 stainless steel and st37 steel, Materials Characterization, 74 (2012) 28-41.

[22] D. Deng, FEM prediction of welding residual stress and distortion in carbon steel considering phase transformation effects, Materials \& Design, 30 (2009) 359-366.

[23] D. Deng, K. Ogawa, S. Kiyoshima, N. Yanagida, K. Saito, Prediction of residual stresses in a dissimilar metal welded pipe with considering cladding, buttering and post weld heat treatment, Computational materials science, 47 (2009) 398-408.

[24] S. Marimuthu, A.M. Kamara, H.K. Sezer, L. Li, G.K.L. Ng, Numerical investigation on laser stripping of thermal barrier coating, Computational materials science, 88 (2014) 131138.

[25] A.M. Kamara, S. Marimuthu, L. Li, A Numerical Investigation into Residual Stress Characteristics in Laser Deposited Multiple Layer Waspaloy Parts, Journal of Manufacturing Science and Engineering, 133 (2011) 031013-031013.

[26] M. Attarha, I. Sattari-Far, Study on welding temperature distribution in thin welded plates through experimental measurements and finite element simulation, Journal of Materials Processing Technology, 211 (2011) 688-694. 
[27] C.-H. Lee, K.-H. Chang, Finite element simulation of the residual stresses in high strength carbon steel butt weld incorporating solid-state phase transformation, Computational materials science, 46 (2009) 1014-1022.

[28] C.-H. Lee, K.-H. Chang, Numerical analysis of residual stresses in welds of similar or dissimilar steel weldments under superimposed tensile loads, Computational materials science, 40 (2007) 548-556.

[29] N. Arivazhagan, S. Singh, S. Prakash, G. Reddy, Investigation on AISI 304 austenitic stainless steel to AISI 4140 low alloy steel dissimilar joints by gas tungsten arc, electron beam and friction welding, Materials \& Design, 32 (2011) 3036-3050. 